\title{
Carpal tunnel syndrome in females: pregnancy and lactation the major risk factors
}

\author{
Sandesh Ganjoo $^{1 *}$, Diptiman Kaul ${ }^{2}$, Parvaiz Ahmed Shah ${ }^{3}$
}

\begin{abstract}
${ }^{1}$ Department of Obstetrics and Gynecology, Guru Gobind Singh Medical College and Hospital, Faridkot, Punjab, India ${ }^{2}$ Department of Cardiology, Dayanand Medical College, Ludhiana, Punjab, India

${ }^{3}$ Department of Medicine, Government Medical College, Srinagar, Jammu and Kashmir, India
\end{abstract}

Received: 17 July 2018

Accepted: 21 July 2018

\author{
*Correspondence: \\ Dr. Sandesh Ganjoo, \\ E-mail: drsandeshganjoo@hotmail.com
}

Copyright: (c) the author(s), publisher and licensee Medip Academy. This is an open-access article distributed under the terms of the Creative Commons Attribution Non-Commercial License, which permits unrestricted non-commercial use, distribution, and reproduction in any medium, provided the original work is properly cited.

\section{ABSTRACT}

Background: Carpal Tunnel Syndrome (CTS) is the most common entrapment neuropathy. CTS is more common in the age group of 45-65 years and more common in women than men. Several factors cause CTS, including pregnancy and lactation.

Methods: The study was conducted on 60 females with carpal tunnel syndrome. Each patient was subjected to detailed history and relevant clinical examination with emphasis on elaborate neurological examination. Informed consent regarding participation into the study was taken from the patients. Patients suspected of suffering from carpal tunnel syndrome were subjected to nerve conduction study. Patients were classified into mild- moderate and severe carpal tunnel syndrome according to clinical and nerve conduction grading.

Results: Out of 60 females, 21 were pregnant (35\%) and 19 were lactating $(31.7 \%)$. The mean age of presentation was $44.6 \pm 14.14$ years with range from 22 to 63 years. Causes were attributed to Pregnancy (35\%) lactation $(31.7 \%)$, hypothyroidism (18.3\%), occupational risk factors $(15.85 \%)$ and gout $(2.4 \%)$.

Conclusions: Carpal tunnel syndrome has a high incidence in females. Sensory symptoms (paresthesia, numbness and nocturnal pain) were more common than symptoms of motor weakness. Dominant hand involvement was more common.

Keywords: Carpal tunnel syndrome, Lactation, Pregnancy, Women

\section{INTRODUCTION}

Carpal Tunnel Syndrome (CTS) is the most common entrapment neuropathy. ${ }^{1,2}$ It is a common focal peripheral nerve compression. It has an estimated life time risk of $10 \%$ with an annual incidence of $0.1 \%$ in adults. ${ }^{3}$ It has an estimated prevalence of $3-16 \%$ with an incidence of 139 per 1,00,000 person years for men and 506 per $1,00,000$ person years for women. ${ }^{1,4}$ CTS is more common in the age group of 45-65 years and more common in women than men. ${ }^{5}$ Several factors cause CTS, including pregnancy and lactation. ${ }^{6,7}$ Since almost all the females go through childbearing more than once in their lives, study on their causal or aggravation of CTS can be of value. The compression of median nerve in the carpal tunnel causes the signs and symptoms of CTS. The condition is usually bilateral, but the dominant hand seems to be more severely affected. ${ }^{8}$ Numbness and paresthesia in the first three fingers are the classical symptom of CTS. ${ }^{1}$ Typically, the symptoms present at night and often awakens the patient from sleep. The common symptoms include: numbness, tingling and burning in median nerve region. ${ }^{2}$ In severe cases, there may be weakness when using hands while doing activities like turning keys, opening doorknobs or opening jar lids. In clinical examination, conventional 
tests for diagnosis of CTS are the Tinels test, Phalens test and the median nerve compression test. ${ }^{2}$ In presence of aggravation of symptoms these tests are considered to be positive. The most accurate test is the electromyogram with a sensitivity of $49-84 \%$ and a specificity of $95 \% .^{1,2}$

The treatment of CTS depends on the severity and can range from applying wrist splints to injecting corticosteroids into the carpal tunnel and eventually releasing the median nerve by surgery. Females have a higher incidence of CTS and pregnancy and lactation are risk factors and increase in intensity is seen in future pregnancies. Since invasive methods are avoided during pregnancy, early detection and treatment with noninvasive methods is of utmost importance.

Till date studies conducted on CTS in pregnant women have not used standard electrodiagnostic methods. ${ }^{3,4,7}$ The confirmatory diagnosis of CTS is the electrophysiological study which is specific to the tune of $95 \%$. These are performed for accurate diagnosis, to determine the exact site of entrapment and to prelude alternative diagnosis which mimic CTS in presentation. ${ }^{9}$

\section{METHODS}

The study was conducted on 60 females with carpal tunnel syndrome reporting to the Medical Outpatient Department of a tertiary care hospital. The study protocol was approved by the institutional ethical committee. Each patient was subjected to detailed history and relevant clinical examination with emphasis on elaborate neurological examination. Informed consent regarding participation into the study was taken from the patients. All the information regarding history and examination was recorded in case record form. Patients suspected of suffering from carpal tunnel syndrome were subjected to nerve conduction study. Patients were classified into mild, moderate and severe carpal tunnel syndrome according to clinical and nerve conduction grading. ${ }^{10}$ Apart from electrophysiological study following investigations were performed whenever deemed necessary, $\mathrm{CBC}, \mathrm{Hb}, \mathrm{ESR}, \mathrm{T} 4, \mathrm{TSH}$, routine serum biochemistry.

\section{Exclusion criteria}

Patients with history of neurologic disease, hand surgery, hand trauma, diabetes mellitus, cervical spondylosis, osteoarthritis of cervical spine or wrist joint, chronic renal failure, connective tissue disorders, patients with no electrophysiological evidence of carpal tunnel syndrome and those who refused to participate in the study were excluded.

\section{Statistical analysis}

Statistical Software SPSS (version 16.0) and Microsoft Excel were used to carry out the statistical analysis of the data. A p value of $<0.05$ using chi- square test was considered statistically significant.

\section{RESULTS}

Out of 60 females, 21 were pregnant (35\%) and 19 were lactating $(31.7 \%)$. The mean age of presentation was $44.6 \pm 14.14$ years with range from 22 to 63 years. Majority of the patients were in the age group of 31 to 40 years. Paraesthesias $(74.39 \%)$, numbness $(63.41 \%)$, pain that worsens at night $(53.65 \%)$ were reported by the studied patients. Weakness of Abductor Pollicis Brevis was seen less frequently $(19.51 \%)$. Thus, it was seen that sensory symptoms dominated over motor symptoms. Tinel's and Phalen's sign were positive in $48.8 \%$ and $57.3 \%$ patients respectively. Risk factors/ causes were attributed to pregnancy (35\%) lactation (31.7\%), hypothyroidism (18.3\%), occupational risk factors (15.85\%) (most common females working in fields) and gout $(2.4 \%)$. In $14.63 \%$ of the patients, the cause could not be identified. Based on clinical assessment, $60 \%$ had mild to moderate CTS and $40 \%$ had severe CTS. However, as classified by NCS, there were $30 \%$ patients with mild to moderate CTS and $70 \%$ with severe CTS. So, a significant number of patients who had mildmoderate CTS on clinical grading actually had severe CTS on electro diagnostic grading $(\mathrm{p}=0.000957)$.

Table 1: Comparison of clinical and electro-diagnostic quantification of the severity of Carpal tunnel syndrome in patients.

\begin{tabular}{|c|c|c|c|c|}
\hline \multirow[t]{2}{*}{ Severity } & \multicolumn{2}{|c|}{ Clinical grading } & \multicolumn{2}{|c|}{$\begin{array}{l}\text { Nerve conduction } \\
\text { grading }\end{array}$} \\
\hline & No. & $\%$ & No. & $\%$ \\
\hline $\begin{array}{l}\text { Mild to } \\
\text { moderate }\end{array}$ & 36 & 60 & 18 & 30 \\
\hline Severe & 24 & 40 & 42 & 70 \\
\hline
\end{tabular}

Dominant hand was involved in $89.02 \%$ of the cases and bilateral CTS was present in $65.8 \%$ of the cases.

\section{DISCUSSION}

In the present study the mean age of presentation was $44.6 \pm 14.141$ years with age ranging from 22 to 63 years Ali $\mathrm{Z}$ et al did a hospital based cross-sectional comparative study to quantify the severity of CTS clinically and electro-diagnostically and to access electrodiagnostic differences between groups with clinically mild to moderate CTS and severe CTS. ${ }^{10} 66$ consecutive patients were taken. Out of 66 patients of CTS, females were $72.7 \%$ and males were $27.3 \%$ and the age ranged from 22-75 years. Bahou YG did a retrospective study on 185 patients with carpal tunnel syndrome over an 18month period. ${ }^{11}$ The mean age of the patients was 45 years with range from 19-80 years. Bicerol B did an electrophysiological and ultrasonographic study of carpal tunnel syndrome. ${ }^{12}$ Tay LB carried out a retrospective 
study and included 134 consecutive patients with CTS and it was found that the majority of patients were females $(81.3$ percent $) .{ }^{1}$ In the present study, paraesthesias were present in $75.60 \%(\mathrm{n}=45)$, numbness in $63.41 \%(n=38)$, pain that worsens at night in $53.65 \%$ $(n=32)$ of the patients. Weakness of Abductor Pollicis Brevis was less frequent $(19.51 \%)(n=12)$. These results were comparable with studies done by other researchers. ${ }^{9}$ Ali $\mathrm{Z}$ et al in their study found paraesthesia (77.3\%), numbness $(63.6 \%)$, pain that worsens at night $(56.1 \%)$, and weakness of APB in $19.7 \%$ of the patients. ${ }^{10}$ In present study, Phalen's test was positive in $57.3 \%(n=34)$ patients and Tinel's test was positive in $48.8 \%(n=29)$ of the patients. These results are consistent with reports in the literature. ${ }^{1,10}$ Meta-analysis have shown an average sensitivity of $68 \%$ and specificity of $73 \%$ for a positive Phalen's test. ${ }^{2}$ A positive Tinel's sign may be less sensitive $(50 \%)$ than Phalen's but has a similar specificity $(77 \%){ }^{2}$ Ali $\mathrm{Z}$ et al in their study found that Tinel's and Phalen's test were positive in $48.5 \%$ and $59.1 \%$ respectively. ${ }^{10}$ Tay $\mathrm{LB}$ et al found paraesthesia (70.1 percent) and numbness (19.4 percent) were the presenting sensory symptoms. ${ }^{1}$ In present study, on the basis of clinical grading, $60 \% \quad(n=36)$ patients had mild to moderate grade and $40 \%(n=24)$ patients had severe grade of CTS. However, on Nerve Conduction Studies, $30 \%(n=18)$ patients had mild to moderate grade and $70 \%$ $(n=42)$ patients had severe grade of CTS and this difference between clinical grading and nerve conduction grading was significant $(\mathrm{p}$ value $=0.000957$ ). Dominant hand was involved in $89.02 \%$ of the cases. Bilateral CTS was present in $65.8 \%$ of the cases. These results are comparable with results of other studies. ${ }^{10}$ Ali $\mathrm{Z}$ et al found that on clinical assessment, $74.3 \%$ had mild to moderate CTS and $25.7 \%$ had severe CTS. ${ }^{10}$ However, classified by NCS, $62.1 \%$ had mild to moderate CTS and $37.9 \%$ had severe CTS and this difference between clinical grade and electrophysiological grade was significant $(\mathrm{p}<0.01)$. Bilateral CTS was seen in $68.2 \%$ of the cases and dominant hand was involved in $87.9 \%$ of the cases. In present study, pregnancy was found to be the most common cause/ risk factor for CTS $(35 \%)(n=21)$, followed by lactation $(31.7 \%)(n=19)$. It has been seen that hormonal fluctuations during pregnancy and lactation lead to fluid retention in the carpal tunnel leading to CTS. ${ }^{13}$ Literature has shown that prevalence of CTS in pregnancy is significant (as high as $62 \%) .{ }^{14}$ Bahrami MH et al evaluated 100 pregnant women by hand symptoms, CTS provocation tests, and standard electro diagnostic studies. ${ }^{15}$ It was found that prevalence of CTS in pregnant women was significant (hand symptoms and clinical signs $36 \%$ and $26 \%$ respectively). In present study, hypothyroidism was found in $18.3 \%$ of the patients. In hypothyroidism there is deposition of glycosaminoglycans, hyaluronic acid and some mucopolysaccharides in subcutaneous tissues. Deposition of these substances on median nerve sheath leads to CTS. ${ }^{16}$ The higher percentage of patients with hypothyroidism may be due to higher prevalence of hypothyroidism in India. ${ }^{17}$ Literature also suggests that association of hypothyroidism with CTS is significant. Karpitskaya et al in 2002 found association between hypothyroidism and CTS significant $(\mathrm{P}=0.02) .{ }^{18}$ Daniel $\mathrm{H}$ et al examined the relation between carpal tunnel release and diabetes mellitus, thyroid disease, inflammatory arthritis, hemodialysis, pregnancy use of corticosteroids and hormone replacement therapy. ${ }^{19}$ It was found that hypothyroidism and CTS had significant association (OR $1.7 ; 95 \%$ CI 1.1, 2.8). In present study gout was found as a risk factor in $2.4 \%$ of the cases. Literature also suggests gout as an infrequent cause for Carpal Tunnel Syndrome. $^{3,9}$ It may be due to lack of patients with Tophaceous gout. Rich JT et al found that out of 2649 carpal tunnel releases, 15 hands in 13 patients had tophaceous gout in carpal tunnel with an incidence of $0.6 \% .^{20}$ In present study occupational risk factors as a cause of CTS was found in $15.85 \%$ patients. These results were comparable with those found in literature. ${ }^{13}$

\section{CONCLUSION}

Carpal tunnel syndrome has a high incidence in females. Sensory symptoms (paraesthesia, numbness and nocturnal pain) were more common than symptoms of motor weakness. Dominant hand involvement was more common. Pregnancy and lactation were the most common co-morbid physiological risk factors/ causes for Carpal tunnel syndrome. Nerve conduction studies provide additional objective evidence in diagnosis and severity assessment of Carpal tunnel syndrome.

\section{Funding: No funding sources}

Conflict of interest: None declared

Ethical approval: The study was approved by the Institutional Ethics Committee

\section{REFERENCES}

1. Tay LB, Urkude R, Verma KK. Clinical profile, electrodiagnosis and outcome in patients with carpal tunnel syndrome: a Singapore perspective. Singapore Med J. 2006;47(12):1049-2.

2. Kothari MJ. Clinical manifestations and diagnosis of carpal tunnel syndrome. Available at: https://www.uptodate.com/contents/carpal-tunnelsyndrome-clinical-manifestations-and -diagnosis.

3. El Miedany Y, Ashour S, Youssef S, Mehanna A, Meky FA. Clinical diagnosis of carpal tunnel syndrome: old tests-new concepts. Joint Bone Spine. 2008 Jul 1;75(4):451-7.

4. Gursoy AE, Kolukisa M, Yildiz GB, Kocaman G, Celebi A, Kocer A. Relationship between electrodiagnostic severity and neuropathic pain assessed by the LANSS pain scale in carpal tunnel syndrome. Neuropsychiatric Dis Treatment. 2013;9:65-71.

5. Commissioning Guide: Treatment of Carpal Tunnel Syndrome. Internet 2017. Available at: https://www.rcseng.ac.uk/-/media/.../boa--carpaltunnel-syndrome-guide-2017.pdf 
6. Clinical practice guidelines on the diagnosis of carpal tunnel syndrome. American Academy of Orthopaedic Surgeons. Internet 2007. Available at: https://www.aaos.org/research/guidelines/cts_guideli ne.pdf

7. Omar SA, Habib SS, Al-Drees AM, Hammad D. Fratio, a surrogate marker of carpal tunnel syndrome. Neurosciences (Riyadh). 2009 Jan;14(1):19-24.

8. Sulaiman ME. Appearance of F-wave during electrophysiological study of carpal tunnel syndrome. Tikrit J Pharmac Sci. 2012;8(2):126-37.

9. Tahririan MA, Moghtaderi A, Aran F. Changes in electrophysiological parameters after open carpal tunnel release. Adv Biomed Res. 2012;1:46.

10. Ali Z, Khan A, Shah SM, Zafar A. Clinical and electro-diagnostic quantification of the severity of carpal tunnel syndrome. Ann Pak Inst Med Sci. 2012;8(4):207-12.

11. Bahou YG. Carpal tunnel syndrome: a series observed at Jordan University Hospital (JUH), June 1999-December 2000. Clinical Neurol Neurosurg. 2002 Jan 1;104(1):49-53.

12. Bicerol B, Keceli M, Copcu E, Kiylioglu N, Bolukbasi O, Akyol A. Electrophysiological and ultrasonographic study of carpal tunnel. Int J Plastic Surg. 2007;5(1).

13. Carpal tunnel syndrome. University of Maryland medical system. Internet 2018. Available at: https://www.umms.org/ummc/patientsvisitors/health-library/medicalencyclopedia/images/carpal-tunnel-syndrome

14. Ablove RH, Ablove TS. Prevalance of carpal tunnel syndrome in pregnant women. WMJ. 2009 Jul;108(4):194-6.
15. Bahrami MH, Rayegani SM, Fereidouni M, Baghbani M. Prevalance and severity of carpal tunnel syndrome (CTS) during pregnancy. Electromyogr Clin Neurophysiol. 2005 Mar;45(2):123-5.

16. Macphail K. Why is Carpal Tunnel Syndrome Associated with Hypothyroidism? Internet May 2012. Available at: http://www.kieranmacphail.com/2012/05/04/why-iscarpal-tunnel-syndrome-associated-withhypothyroidism.

17. Bagcchi S. Hypothyroidism is still prevalent in India despite promotion of iodised salt, study shows. British Med J. 2013;347:f7693.

18. Karpitskaya Y, Novak CB, Mackinnon SE. Prevalence of smoking, obesity, diabetes mellitus, and thyroid disease in patients with carpal tunnel syndrome. Annals Plastic Surg. 2002 Mar;48(3):26973.

19. Solomon DH, Katz JN, Bohn R, Mogun H, Avorn J. Nonoccupational risk factors for carpal tunnel syndrome. J Gen Intern Med. 1999 May;14(5):310-4.

20. Rich JT, Bush DC, Lincoski CJ, Harrington TM. Carpal tunnel syndrome due to tophaceous gout. Orthopaedics. 2004 Aug;27(8):862-3.

Cite this article as: Ganjoo S, Kaul D, Shah PA. Carpal tunnel syndrome in females: pregnancy and lactation the major risk factors. Int J Reprod Contracept Obstet Gynecol 2018;7:3512-5. 